\title{
Efetividade da "multimistura" como suplemento de dietas deficientes em vitaminas e/ou minerais na recuperação ponderal de ratos submetidos à desnutrição pós-natal ${ }^{1}$
}

\section{The effectiveness of the "multi-mixture" as supplement to mineral and/or vitamin deficient diets, promoting weight gain in rats submitted to post-natal under-nourishment}

Haroldo da Silva FERREIRA²

Monica Lopes de ASSUNÇÃO ${ }^{3}$

Adijane Oliveira Santos de FRANÇA ${ }^{4}$

Eliana Paiva Cunha CARDOSO ${ }^{5}$

Fabiana Andréa MOURA²

\section{RE S U M O}

\section{Objetivo}

Avaliar a efetividade da "multimistura", usada como suplemento de dietas deficientes em vitaminas, deficientes em minerais, ou deficientes em vitaminas e minerais, na recuperação ponderal de ratos desnutridos.

\section{Métodos}

Após o desmame, 56 ratos Wistar, submetidos à desnutrição pós-natal, foram aleatoriamente distribuídos em 7 grupos diferenciados segundo o tipo de dieta oferecida: controle, dietas deficientes em vitaminas, deficientes em minerais, deficientes em vitaminas e minerais e os grupos cujas dietas deficientes eram suplementadas com a "multimistura" (dietas deficientes em vitaminas + "multimistura", deficientes em minerais + "multimis-

\footnotetext{
1 Apoio financeiro da Fundação de Amparo à Pesquisa do Estado de Alagoas. (Processo 2002/08.057-03).

2 Departamento de Nutrição, Universidade Federal de Alagoas. Av. Lourival de Melo Mota, s/n, Campus A.C. Simões, Tabuleiro dos Martins, 57072-970, Maceió, AL, Brasil. Correspondência para/Correspondence to: H.S.FERREIRA. E-mail: <haroldo@fapeal.br>.

${ }^{3}$ Curso de Nutrição, Centro de Ensino Superior de Maceió, Fundação Jayme de Altavyla. Maceió, AL, Brasil.

4 Bolsista de Aperfeiçoamento da Fundação de Amparo à Pesquisa do Estado de Alagoas (FAPEAL).

5 Acadêmica, Curso de Graduação em Nutrição, Universidade Federal de Alagoas. Maceió, AL, Brasil. Bolsista de Iniciação Científica do PIBIC/CNPq.
} 
$64 \mid$ H.S. FERREIRA et al.

tura" e deficientes em vitaminas e minerais + "multimistura"). A "multimistura" (pó de casca de ovo, pó de folha de mandioca e farelo de trigo, na proporção de 1:1.8) foi adicionada ao nível de 4\%. O ganho ponderal e os Coeficientes de Eficiência Protéica ou alimentar foram usados como indicadores da efetividade da "multimistura" como suplemento de vitaminas e/ou minerais.

\section{Resultados}

Após 28 dias, todos os grupos apresentaram valores de ganho ponderal, coeficientes de eficiência protéica, e coeficientes de eficiência alimentar, inferiores aos do grupo controle $(p<0,05)$, exceto aquele que recebeu dietas deficientes em vitaminas + "multimistura". O grupo que recebeu dieta deficiente em minerais apresentou os piores resultados. A suplementação dessa dieta com a "multimistura" determinou a obtenção de valores significantemente superiores, mas aquém daqueles observados no grupo controle.

\section{Conclusão}

Esses resultados sugerem que a suplementação de dietas pouco nutritivas com a "multimistura", fornece as necessidades de vitaminas de ratos desnutridos e supre apenas parte das necessidades de minerais desses animais.

Termos de indexação: casca de ovo, desnutrição protéica, folha de mandioca, misturas vegetais, ratos, suplementos dietéticos.

\section{A B S T R A C T}

\section{Objective}

To investigate the effectiveness of the "multi-mixture", consisting of powdered eggshell, powdered cassava leaf and wheat bran (1:1:8), as a vitamin and/or mineral supplement in the promotion of weight gain in undernourished rats.

\section{Methods}

After weaning, 56 Wistar rats which had been submitted to under-nutrition since birth, were divided randomly into 7 groups, according to the diet supplied, namely: control, vitamin deficient, mineral deficient, vitamin and mineral deficient, vitamin deficient supplemented with "multi-mixture", mineral deficient supplemented with "multi-mixture", and vitamin and mineral deficient supplemented with "multi-mixture". The recorded weight gains during the treatment period, together with the protein efficiency ratios and the food efficiency ratios, were taken as indicators of the efficiency of "multi-mixture" as a vitamin and/or mineral supplement.

\section{Results}

After 28 days, gains in body weight and the values of protein efficiency ratios and food efficiency ratios were significantly lower $(p<0.05)$ than those of the control group for all treatment groups except for that fed on vitamin deficient supplemented with "multi-mixture". The lowest indicator levels were observed in the group fed on mineral deficient: supplementation of this diet with "multi-mixture" lead to significant improvements in weight gain, protein efficiency ratios and food efficiency ratios, but to values still below those obtained for the control group.

\section{Conclusion}

The results suggest that supplementation with "multi-mixture" of diets low in nutritional value can provide the required vitamins, but only part of the mineral requirements of undernourished rats.

Indexing terms: egg shell, protein malnutrition, cassava leaf, vegetable mixtures, rats, dietary supplements. 


\section{N T R O D U Ç Ã O}

Apesar das evidências de que o Brasil esteja passando por um processo de transição nutricional e das reiteradas vezes em que os países membros das Nações Unidas têm reafirmado o compromisso de garantir o direito de todo ser humano de não padecer de fome', a desnutrição infantil continua sendo um grave problema de saúde pública em nosso País, devido à sua magnitude e aos conseqüentes prejuízos para o crescimento, desenvolvimento e sobrevivência da criança ${ }^{2,3}$.

No Brasil, a partir da década de 70, houve redução na ordem de um terço na prevalência de desnutrição entre os menores de 5 anos, sendo que, especificamente para as formas moderadas ou graves, essa redução foi de quase dois terços ${ }^{4}$. No entanto, o problema está longe de ser controlado. Conforme dados da Pesquisa Nacional sobre Saúde e Nutrição (1989), 17,3\% das crianças brasileiras apresentam déficit de peso para idade e $26,9 \%$, déficit de estatura para idade, sendo que, entre as crianças de menor nível socioeconômico, observam-se freqüências ainda maiores: $31,8 \%$ e $41,4 \%$, respectivamente. É importante destacar que mais da metade desses desnutridos encontra-se na região Nordeste do Brasil ${ }^{5}$. Esses dados, baseados em médias populacionais, mascaram a gravidade com que a desnutrição acomete certos grupos sob condições especiais de risco nutricional. Em alguns estudos conduzidos em favelas em Alagoas, temos encontrado quase $50,0 \%$ das crianças com desnutrição crônica e mais de 93,0\% acometidas pela anemia ${ }^{6,7}$.

Segundo Mahler ${ }^{8}$, sendo a desnutrição um produto da pobreza e da privação, em última instância, só poderá ser erradicada mediante uma ação política orientada a reduzir as desigualdades entre países e entre os habitantes de um mesmo país. Na ausência dessa política, a sociedade civil organizada busca soluções alternativas para dar respostas ao problema apresentado.

No contexto dessas ações, surgiu a proposta da alimentação alternativa, tendo por base o conceito que nem sempre se aproveita o alimento integralmente, de modo que folhas, cascas e sementes descartadas como lixo, seriam potencialmente nutritivas ${ }^{9}$. Esse conceito teve como principal desdobramento a elaboração da chamada "multimistura" (MM), um farelo formulado a partir desses subprodutos e usado como suplemento à alimentação habitual de crianças. Os principais argumentos apresentados pelos defensores de sua adoção como medida de prevenção e tratamento da desnutrição ${ }^{9}$ são a disponibilidade regional de seus ingredientes, a não interferência nos hábitos alimentares da população, o baixo custo, a possibilidade de preparação caseira e a acessibilidade a, praticamente, toda a população. Esses aspectos têm contribuído para sua utilização crescente por profissionais de saúde em grande número de municípios brasileiros.

No entanto, a proposição da "multimistura" como alternativa de combate à desnutrição tem recebido muitas críticas no meio acadêmico, em virtude da alegação da falta de comprovação científica de seus efeitos, ausência de controle sanitário relativo à sua preparação, assim como pela inadequação desses subprodutos para o uso humano, devido à possível ocorrência de toxinas e fatores antinutricionais ${ }^{1-14}$.

Embora se reconheça a presença de quantidades importantes de minerais e vitaminas na MM, argumenta-se que o valor nutritivo de qualquer alimento não pode ser estabelecido unicamente com base em sua composição química, haja vista que uma série de fatores tais como o equilíbrio de seus constituintes, as interações entre diversos compostos da dieta (ou do próprio alimento), o estado fisiológico do indivíduo, as condições de processamento e armazenamento e a ocorrência de antinutrientes, podem interferir na utilização desses nutrientes ${ }^{15}$.

No intuito de contribuir para a discussão dessa problemática, realizou-se o presente trabalho, objetivando avaliar a efetividade da "multimistura" como suplemento vitamínico e/ou mineral na recuperação ponderal de ratos submetidos à desnutrição pós-natal. 


\section{MATERIALE MÉTODOS}

\section{Fase I - Depleção nutricional}

Foram utilizados 56 ratos albinos (Rattus norvegicus) machos, da linhagem Wistar, procedentes do Biotério Central da Universidade Federal de Alagoas. Imediatamente após o nascimento, passava-se a oferecer às matrizes, juntamente com uma ninhada padronizada em 12 crias, a Dieta Básica Regional (DBR $)^{16}$, mantendo-se esse regime até o dia do desmame (21 dias). A DBR foi estabelecida a partir de inquéritos dietéticos, conduzidos na Zona da Mata de Pernambuco, sendo constituída de (g/100g) $18,3 \mathrm{~g}$ de feijão mulatinho, $64,8 \mathrm{~g}$ de farinha de mandioca, $4,1 \mathrm{~g}$ de charque e $12,8 \mathrm{~g}$ de batata doce e apresentando a seguinte composição centesimal: proteína (7,8\%), carboidrato $(73,2 \%)$, gordura (1,5\%), fibras $(7,2 \%)$, cinzas $(1,3 \%)$ e umidade $(9,0 \%)$. Atualmente, vem sendo usada como modelo experimental para estudo da desnutrição, por induzir, no rato, quadro carencial semelhante ao marasmo verificado em populações humanas. Nesse experimento, os animais apresentaram, ao desmame, um peso médio equivalente a $52,5 \%$ daquele atingido pelos animais padrões do Biotério Central da Universidade Federal de Alagoas $(26,5 \pm 1,9 \mathrm{~g}$ vs $50,5 \pm 3,6 \mathrm{~g})$.

\section{Fase II - Repleção nutricional}

Imediatamente após o desmame (fase I), os animais foram aleatoriamente distribuídos em 7 grupos $(n=8)$, segundo o tipo de dieta e mantidos em gaiolas individuais, em ambiente com controle de temperatura $\left(23^{\circ} \pm 2^{\circ} \mathrm{C}\right)$ e ciclo claro-escuro de 12 em 12 horas, recebendo água desionizada e a dieta correspondente ad libitum. A dieta foi fornecida na forma pulverizada. Todos os materiais utilizados eram de aço inoxidável, vidro ou plástico, para minimizar qualquer ingestão de minerais além daqueles fornecidos dieteticamente.

Nessa fase, além da dieta controle (AIN-93G) ${ }^{17}$, foram utilizadas 6 dietas, semelhantes em todos os aspectos à dieta controle, porém, com apenas $20 \%$ das recomendações, respectivamente, de vitaminas, de minerais ou de ambos, suplementadas ou não com a MM. O nível protéico das dietas, estabelecido em $20 \%$, foi controlado por meio do método de Kjedahl18.

Tabela 1. Composição das dietas controle e das dietas deficientes em vitaminas, minerais ou vitaminas e minerais, suplementadas ou não com a "multimistura".

\begin{tabular}{lccccccc}
\hline \multirow{2}{*}{ Ingredientes } & \multicolumn{7}{c}{ Dietas (g\%) } \\
\cline { 2 - 8 } & Controle & \multicolumn{1}{c}{ dVIT } & dMIN & dVITMIN & dVIT+MM & MIN+MM & dVITMIN + MM \\
\hline Caseína & 20,0000 & 20,0000 & 20,0000 & 20,0000 & 20,0000 & 20,0000 & 20,0000 \\
Amido & 62,9000 & 63,7000 & 65,7000 & 66,5000 & 59,7000 & 61,7000 & 62,5000 \\
Óleo de soja & 7,0000 & 7,0000 & 7,0000 & 7,0000 & 7,0000 & 7,0000 & 7,0000 \\
Celulose & 5,0000 & 5,0000 & 5,0000 & 5,0000 & 5,0000 & 5,0000 & 5,0000 \\
Minerais & 3,5000 & 3,5000 & 0,7000 & 0,7000 & 3,5000 & 0,7000 & 0,7000 \\
Vitaminas & 1,0000 & 0,2000 & 1,0000 & 0,2000 & 0,2000 & 1,0000 & 0,2000 \\
Metionina & 0,3000 & 0,3000 & 0,3000 & 0,3000 & 0,3000 & 0,3000 & 0,3000 \\
Colina & 0,2500 & 0,2500 & 0,2500 & 0,2500 & 0,2500 & 0,2500 & 0,2500 \\
Hidroquinona & 0,0014 & 0,0014 & 0,0014 & 0,0014 & 0,0014 & 0,0014 & 0,0014 \\
"multimistura" & - & - & - & - & 4,0000 & 4,0000 & 4,0000 \\
\hline Total & 100,0000 & 100,0000 & 100,0000 & 100,0000 & 100,0000 & 100,0000 & 100,0000 \\
\hline
\end{tabular}

Nota: As dietas deficientes tinham, respectivamente, apenas 20\% das quantidades de vitaminas e/ou minerais preconizadas para a dieta controle; a caseína ( $80 \%$ de proteína), as misturas de vitaminas e minerais, a celulose, a metionina, a hidroquinona e o bitartarato de colina foram adquiridos na Rhoster - São Paulo; a "multimistura" foi adquirida na Pastoral da Criança - Maceió, AL. dVIT= dieta deficiente em vitaminas, dMIN= dieta deficiente em minerais, dVITMIN= dieta deficiente vitaminas e minerais, MM= "multimistura". 
Na ausência de padronização quanto à quantidade de $\mathrm{MM}$ a ser acrescida às dietas experimentais, decidimos utilizá-la na proporção de $4 \mathrm{~g} / 100 \mathrm{~g}$ de dieta. A Tabela 1 apresenta a composição das dietas utilizadas.

A MM foi adquirida junto à Pastoral da Criança de Maceió. Era composta de 10\% de pó de casca de ovo, 10\% de folha de mandioca (Manihot esculenta) e $80 \%$ de farelo de trigo (Tritium aestivum L.). Esses ingredientes, após dessecagem e pulverização, eram homogeneizados, submetidos à torrefação durante 10 minutos em fogo baixo, visando à destruição de microorganismos e à inativação de substâncias tóxicas. Sua composição centesimal aproximada foi determinada por Siqueira et a $/{ }^{19}$, sendo assim constituída: proteína $(16,0 \mathrm{~g})$, carboidrato $(54,0 \mathrm{~g})$, lipídeos $(5,0 \mathrm{~g})$, cálcio $(3,67 \mathrm{~g})$, ferro $(4,0 \mathrm{mg})$, zinco (9,0mg) e fósforo (885,0mg).

Todos os animais eram pesados semanalmente e tinham sua ingestão alimentar controlada. Ao final de 28 dias, o valor biológico das dietas foi avaliado por meio dos seguintes indicadores: Coeficiente de Eficiência Protéica operacional (CEP), Coeficiente de Eficiência Alimentar (CEA) e Ganho em Peso (GP).
A análise estatística foi procedida por meio de análise de variância para um fator (ANOVA), seguida do teste de amplitude de Duncam para análises múltiplas ${ }^{20}$. Consideraram-se as diferenças como estatisticamente significantes quando $p<0,05$.

Aspectos éticos: todos os procedimentos experimentais obedeceram às normas do Comitê de Bioética e Ética em Pesquisa da Universidade Federal de Alagoas, em conformidade com as diretrizes do Conselho Nacional de Ética em Pesquisa, Conselho Nacional de Saúde.

\section{RESULT A D O S}

As três dietas deficientes promoveram Ganho em Peso, CEP e CEA inferiores aos obtidos com a dieta controle (Tabela 2). Essas dietas, quando suplementadas com a MM, melhoraram significantemente sua qualidade $(p<0,05)$. No entanto, apenas o grupo alimentado com a dieta deficiente em vitaminas, suplementada com a MM, atingiu o nível daquele que recebeu a dieta controle, sugerindo que a MM foi efetiva em atender as necessidades vitamínicas dos animais.

Tabela 2. Valores de consumo alimentar, ganho de peso e Coeficientes de Eficiência Protéica e Alimentar dos animais desnutridos e alimentados por 28 dias com as dietas controle ou deficientes em vitaminas, minerais ou vitaminas e minerais suplementadas ou não com a "multimistura".

\begin{tabular}{|c|c|c|c|c|c|c|c|c|c|c|}
\hline \multirow{2}{*}{ DIETAS } & \multirow[b]{2}{*}{$\mathrm{n}$} & \multicolumn{2}{|c|}{ Consumo Alimentar (g) } & \multicolumn{2}{|c|}{ Ganho em peso (g) } & \multicolumn{2}{|r|}{ CEP } & \multicolumn{3}{|c|}{ CEA } \\
\hline & & M & DP & $\mathrm{M}$ & $\mathrm{DP}$ & $\mathrm{M}$ & DP & $\mathrm{M}$ & & DP \\
\hline Controle & 8 & 216,30 & $\pm 33,50$ & 103,80 & $\pm 20,90$ & 2,53 & $\pm 0,36$ & 0,48 & \pm & 0,07 \\
\hline$d V I T$ & 8 & 207,50 & $\pm 31,00$ & 66,40 & $\pm 9,90 *$ & 1,72 & $\pm 0,36^{*}$ & 0,32 & \pm & $0,07 *$ \\
\hline$d V I T+M M$ & 8 & 217,20 & $\pm 20,80$ & 91,20 & 9,30 & 2,25 & $\pm 0,26$ & 0,42 & \pm & 0,04 \\
\hline Diferença significante & & Não & & Sim & & Sim & & Sim & & \\
\hline $\mathrm{dMIN}$ & 8 & 187,70 & $\pm 34,40$ & 50,70 & $\pm 11,70 *$ & 1,39 & $\pm 0,19 *$ & 0,27 & \pm & $0,04^{*}$ \\
\hline $\mathrm{dMIN}+\mathrm{MM}$ & 8 & 193,20 & $\pm 51,20$ & 69,60 & $\pm 16,20 *$ & 1,84 & $\pm 0,50 *$ & 0,36 & \pm & $0,09 *$ \\
\hline Diferença significante & & Não & & Sim & & Sim & & Sim & & \\
\hline dVITMIN & 8 & 178,10 & $\pm 40,70 *$ & 48,10 & $\pm 15,50 *$ & 1,44 & $\pm 0,20 *$ & 0,27 & \pm & 0,04 * \\
\hline dVITMIN + MM & 8 & 169,20 & $\pm 28,90$ * & 54,10 & $7,10 *$ & 1,63 & $\pm 0,31 *$ & 0,32 & \pm & 0,06 * \\
\hline Diferença significante & & Não & & Não & & Não & & Não & & \\
\hline
\end{tabular}

Diferença significante $(p<0,05)$ comparando a respectiva dieta deficiente com ou sem adição de MM. O * indica diferença significante em relação ao grupo controle. $C E P=$ coeficientes de eficiência protéica, CEA= coeficientes de eficiência alimentar, dVIT= deficientes em vitaminas, $\mathrm{dMIN}=$ deficientes em minerais, dVITMIN= deficientes em vitaminas e minerais, MM= "multimistura". 
Ainda na Tabela 2, verifica-se que os animais ingeriram a dieta deficiente em vitaminas, com ou sem "multimistura", de forma semelhante ao consumo verificado pelos animais que receberam dieta controle. Já em relação às dietas deficientes em minerais, os dados revelam uma tendência à redução do consumo, que só no caso da dupla deficiência (vitaminas e minerais), independentemente da suplementação com MM, apresentou significância estatística em relação à ingestão dietética do grupo controle.

Os animais alimentados com a dieta deficiente em minerais, suplementada com a MM, embora não tenham atingido os valores de ganho de peso, CEP e CEA observados entre os que se alimentaram com a dieta controle, apresentaram resultados significantemente superiores aos que se alimentaram com a mesma dieta, porém sem a suplementação com a MM. A esse respeito, deve-se considerar que a magnitude da desnutrição induzida pela dieta deficiente em minerais (peso final $=50,7 \mathrm{~g}$ ) foi superior à observada com a dieta deficiente em vitaminas (peso final $=66,4 \mathrm{~g}$ ). De acordo com os dados demonstrados (Tabela 3), a suplementação dessas dietas com a MM induziu incrementos de peso proporcionalmente iguais: 37,3\%. Apesar disso, tal fato sugere que a "multimistura" atendeu apenas parcialmente aos requerimentos minerais dos animais, não sendo possível, com o presente modelo experimental, concluir se essa insuficiência deveu-se à quantidade e/ou à biodisponibilidade dos minerais presente na "multimistura".
As curvas de crescimento dos animais indicam que a desnutrição foi mais grave entre aqueles que receberam a dieta deficiente em minerais (Figura 1). Verificou-se que, desde o início do experimento, os grupos que receberam esta dieta ou a duplamente deficiente, apresentaram ritmo de crescimento sistematicamente inferior ao dos demais grupos, enquanto aquele que recebeu a dieta deficiente em vitaminas, só a partir da última semana de experimentação, apresentou queda no ritmo de crescimento, fato não observado no grupo que recebeu esta mesma dieta, (deficiente em vitaminas), suplementada com a MM. Observa-se, no entanto, que, em nenhum momento do experimento, houve superposição da curva de crescimento deste grupo com a do grupo controle. Este dado, aliado ao fato de a MM não ter melhorado a qualidade da dieta duplamente deficiente, sugere um efeito sinérgico entre as duas deficiências e suscita a possibilidade de que o suprimento vitamínico também não tenha sido suficiente, agravando ainda mais os efeitos da deficiência mineral.

\section{I S C U S S Ã O}

Estudos bromatológicos têm encontrado altas concentrações de minerais (ferro, cálcio, zinco, cobre, manganês, selênio) e vitaminas ( $A$, $\mathrm{B}_{2}, \mathrm{~B}_{6}, \mathrm{C}$, ácido fólico, ácido pantotênico e biotina) na "multimistura" ou em seus componentes ${ }^{21,22}$, o que explicaria sua efetividade como suplemento vitamínico, conforme os resultados ora apresen-

Tabela 3. Efeito da suplementação com a "multimistura" sobre o ganho de peso de animais alimentados com dietas deficientes em vitaminas e/ou minerais.

\begin{tabular}{lccc}
\hline \multirow{2}{*}{ Dieta } & Ganho de peso após 28 anos & Incremento (\%) \\
\cline { 2 - 3 } & Sem "multimistura" & Com "multimistura" & \\
\hline Controle & 103,800 & - & 37,300 \\
Deficiente em vitaminas & 66,400 & 91,200 & 37,300 \\
Deficiente em minerais & 50,700 & 69,600 & 0,006 \\
Deficiente em vitaminas e minerais & 48,100 & 54,100 & 0,010 \\
\hline
\end{tabular}




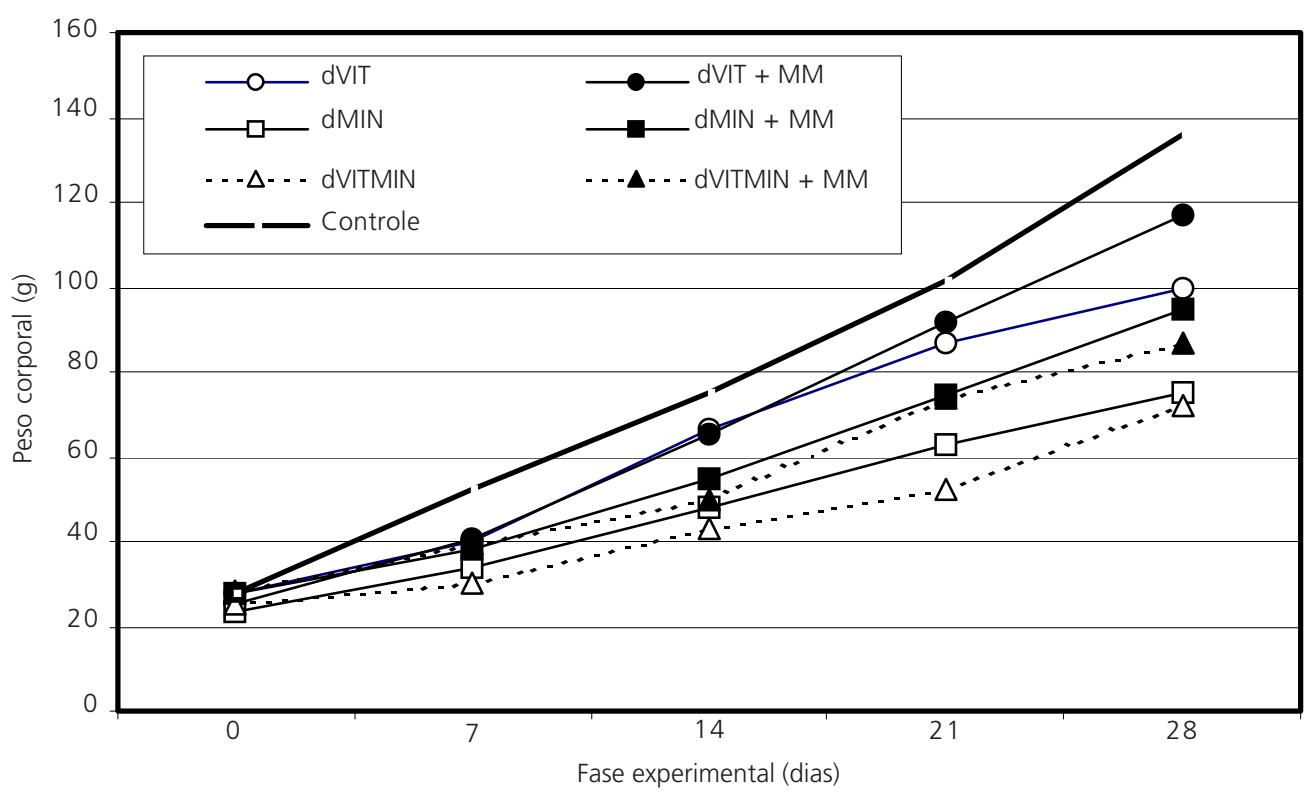

Figura 1. Curva de crescimento de animais previamente desnutridos e alimentados com a dieta controle ou deficientes em vitaminas $(\mathrm{dVIT})$, minerais (dMIN) ou vitaminas e minerais (dVITMIN), suplementadas ou não com a "multimistura" (MM).

tados. Por outro lado, a relativamente baixa efetividade como suplemento mineral verificada, talvez se justifique pelo fato de que o zinco, o ferro, o cobre e o cálcio, em determinadas concentrações, interferem mutuamente nas suas taxas de utilização ${ }^{23}$. Ademais, cumpre observar que a MM possui teores importantes de fitatos, oxalatos e fibra dietética, os quais podem reduzir a biodisponibilidade dos minerais ${ }^{23}$.

Entretanto, Siqueira et al. ${ }^{24}$, investigando a biodisponibilidade de cálcio, ferro e zinco em ratos, alimentados com dieta deficiente suplementada com MM, à qual adicionaram-se várias proporções de fitato e minerais, concluíram que o teor de fitato não prejudicou a biodisponibilidade desses minerais. Os autores enfatizam que a atividade de fitase em ratos é superior à observada em humanos, o que poderia ter influenciado os resultados. Por outro lado, argumenta-se que a molécula de fitato (hexafosfato de inositol), quando submetida a processamento a quente, vai perdendo seus radicais fosfatos, passando de hexa a penta, tetra e trifosfato. Essa alteração vai reduzindo o seu poder de inibir a absorção intestinal dos nutrientes ${ }^{25}$. Como o farelo de trigo, o principal ingrediente e importante fonte de fitato no preparo da MM, é submetido a torrefação, considera-se provável que este processo tenha atenuado seu efeito adverso.

Câmara \& Madruga ${ }^{26}$ analisaram a "multimistura" utilizada como suplemento em programas institucionais da Secretaria Municipal de Promoção Social da cidade de Natal, encontrando baixíssimas concentrações de fitatos e taninos e níveis não detectáveis de aflatoxinas e ácido cianídrico.

Arruda ${ }^{27}$ investigou a capacidade de recuperação de ratos desnutridos e a biodisponibilidade do cálcio, ferro e zinco de dietas suplementadas com diferentes proporções de MM. Concluiu que a adição de, pelo menos, $2 \%$ de MM na dieta proporcionou a recuperação do pêlo, ganho de peso e deposição de cálcio no fêmur cinco vezes maior que os valores verificados nos ratos mantidos em dieta basal (arroz polido e óleo vegetal). Foi possível observar que 5\% de MM adicionada à dieta, ajuda o indivíduo a se recuperar da anemia, sugerindo que o teor de fitato na $\mathrm{MM}$ não é fator limitante no 
desenvolvimento dos ratos. Segundo o autor, o reduzido teor protéico e ausência de microelementos como sódio, cloro, flúor e iodo, na MM, provavelmente, limitem sua efetividade na recuperação plena da desnutrição em ratos. Talvez esses achados expliquem os resultados obtidos em nosso trabalho (baixa efetividade da MM como suplemento mineral), já que não é consistente, à luz da literatura disponível, a hipótese de baixa biodisponibilidade dos componentes da MM em decorrência da presença de antinutrientes.

Um dos óbices apresentados pelos pesquisadores que se contrapõem ao uso da MM, diz respeito à dificuldade no controle de seu padrão microbiológico e/ou físico-químico. Dentre os vários lotes de MM que enviamos para análise em dois laboratórios independentes, encontraram-se desde lotes perfeitos do ponto de vista higiênico-sanitário até outros considerados impróprios para consumo, em decorrência da presença de resíduos estranhos, restos de insetos e valores de coliformes fecais acima do permitido.

Vários estudos realizados com o intuito de avaliar a efetividade da MM têm encontrado resultados satisfatórios.

Bicudo et al. ${ }^{28}$ concluíram que o acréscimo de $\mathrm{MM}$ à dieta que induziu desnutrição, foi benéfico na recuperação ponderal de ratos, embora o resultado obtido tenha sido em intensidade menor que o observado na dieta padrão.

Santos et al. ${ }^{29}$ avaliaram o valor biológico da proteína da Farinha de Pena integral ou hidrolisada, utilizando a MM como complemento de sais minerais. Ratos desnutridos receberam dieta à base dessas fontes protéicas com redução de $75 \%$ de sais minerais, com adição ou não de MM. As dietas com redução de sais minerais, suplementadas com MM, proporcionaram melhor desempenho em termos de crescimento dos animais.

Siqueira et al. ${ }^{19}$ investigaram a efetividade da suplementação de MM, concomitantemente com outras ações destinadas a melhorar a saúde de crianças. Trinta e um estudantes matriculados em uma escola rural foram examinados (antropometria e hematologia), antes e após o consumo de dieta suplementada com MM. Os resultados foram comparados com aqueles do grupo controle ( $n=26)$, que consumiu a mesma dieta, sem MM. Após 6 meses de intervenção, verificou-se que as ações gerais de saúde causaram efeito benéfico na condição nutricional das crianças, tendo em vista que melhoraram seus parâmetros hematológicos, independentemente da MM. Os valores médios para o índice estatura para idade foram significantemente mais elevados no grupo que recebeu a MM. Concluíram que a suplementação de dietas deficientes com MM contribuiu para a melhoria da estatura de crianças.

Outros estudos, no entanto, concluíram pela ineficácia da "multimistura".

Bion et al..$^{30}$ estudaram os efeitos da MM sobre o valor nutritivo de uma associação alimentar de feijão com arroz, concluindo que a mesma não exerceu efeitos notórios sobre os diversos parâmetros nutricionais estudados.

Leite et al. ${ }^{31}$ avaliaram o desempenho lactacional de ratas alimentadas com dieta suplementada com $2 \%$ de "multimistura" (MM), concluindo que a performance lactacional das ratas apresentou-se diminuída.

Azeredo et al. ${ }^{32}$ determinaram, em ratas, a influência da "multimistura" (MM) sobre o ganho de peso materno e fetal e sobre a hipertrigliceridemia materna no final do período gestacional. Concluíram que a utilização da "multimistura", na proporção usada durante a gestação, não possui nenhum efeito sobre os parâmetros estudados.

Uma dificuldade relacionada ao estudo da efetividade da MM como suplemento dietético, decorre da própria concepção de sua proposta: a MM não tem uma composição uniforme. Devem-se utilizar os recursos disponíveis localmente. Por esse motivo, é difícil encontrar um estudo cuja composição da MM seja semelhante à investigada 
por um outro laboratório. Esse aspecto, certamente, contribui para a obtenção de resultados conflitantes. A propósito, durante os nossos primeiros contatos com a equipe da Pastoral da Criança de Maceió (Alagoas, Brasil), responsável pela elaboração e distribuição da MM, sugerimos a não utilização de fontes de carboidratos em sua formulação, já que o objetivo da suplementação seria vitamínica e mineral. A partir de então, ingredientes como a farinha de trigo ou de mandioca e o fubá de milho, que integravam sua composição numa proporção de quase $67 \%$, deixaram de ser utilizados. Alguns estudos têm sido realizados utilizando "multimisturas" elaboradas com essas fontes de carboidratos. Esses alimentos, embora sejam fontes energéticas importantes, quando veiculados pela MM, além de não cumprirem essa função, em virtude da pouca quantidade fornecida pela suplementação (cerca de 2 colheres de sopa/dia), promovem diluição dos nutrientes presentes na MM.

Em nível institucional, vários municípios brasileiros vêm utilizando a MM em suas ações para controle da desnutrição. Em Belo Horizonte, MG, essa ação foi instituída em 1993, no âmbito do Programa de Prevenção e Combate à Desnutrição, abrangendo inicialmente 51 Centros de Saúde (CS). Em 1996 o programa já estava implantado em 116 CS, contando, ainda, com a participação de cerca de 200 voluntárias da Pastoral da Criança. Nesse ano, foram atendidos 15009 menores de 5 anos e 4885 gestantes e nutrizes. Além da distribuição da MM, o Programa contempla várias ações básicas de saúde, consideradas efetivas e internacionalmente recomendadas. De acordo com relatório técnico da Secretaria de Saúde, em 1995 a mortalidade infantil caiu de 34,4/1000 nascidos vivos, para 29,3/1000. Segundo o relatório, a redução da desnutrição como causa básica, contribuiu para o decréscimo da mortalidade, já que fora responsável por 12,3\% dos óbitos em 1993, passando para $6,5 \%$ em 1995. Quanto à evolução das crianças desnutridas, observou-se que 39,0\% melhoraram o estado nutricional; $56,0 \%$ mantiveram-se inalteradas e 5,0\% apresentaram deterioração do quadro inicial ${ }^{33}$. Na avaliação da efetividade do uso da MM no contexto desse Programa, duas questões devem ser destacadas: 1) A ausência de um grupo controle não permite atribuir à $\mathrm{MM}$ os resultados obtidos, pois se sabe que as demais ações empreendidas contribuem para a melhoria dos indicadores utilizados; 2) a MM utilizada, chamada farinha enriquecida, possuía em sua composição $30,0 \%$ de leite em pó integral, condição válida para os propósitos locais, humanitários, mas que dificulta a análise da qualidade específica da MM, tal como foi originalmente proposta.

\section{CONSIDERAÇÕ ES FINAIS}

A desnutrição como problema de saúde pública é determinada por uma complexa rede de causalidade, cujos fatores podem ser categorizados em três níveis: imediatos, subjacentes e básicos. Portanto, na atenção a esse problema, as ações terão, também, idênticos níveis de alcance. Considerando como causa básica a dificuldade de acesso ao alimento, em virtude de uma precária condição socioeconômica das famílias, entende-se que só medidas macroeconômicas podem, definitivamente, reduzir as alarmantes prevalências de desnutrição encontradas em algumas localidades brasileiras, sobretudo em comunidades específicas das regiões mais pobres do País².

Apesar desse entendimento, tem sido demonstrada a importância de medidas menos abrangentes. Em artigo publicado por Monteiro et al. ${ }^{34}$, os autores observaram redução da ordem de 50,0\% na taxa de mortalidade infantil em São Paulo, no período de 1973 a 1983, sem que, no entanto, tenha havido mudanças marcantes nas características socioeconômicas da população. Atribuiu-se a responsabilidade por tal redução ao aumento da cobertura populacional pelos serviços de saúde.

Na ação contra as causas subjacentes de desnutrição, estão as medidas que atuam sobre 
os fatores responsáveis pelo tipo específico de ingestão alimentar inadequada e sobre as doenças que levam à desnutrição ou à morte de crianças. Entre essas ações, destacam-se a imunização, o incentivo ao aleitamento materno, a ampliação e melhoria do sistema de atenção primária à saúde, a educação em saúde e nutrição, o planejamento familiar, a segurança alimentar familiar, a assistência materno-infantil, o saneamento básico e o abastecimento de água, a alfabetização e a educação.

Entre as medidas que atacam as manifestações e as causas imediatas, aquelas direcionadas a ajudar as crianças já afetadas pela desnutrição e pelas doenças, ou que tenham uma ingestão alimentar inadequada, destacam-se a recuperação nutricional, o fornecimento de alguns medicamentos essenciais, a terapia de reidratação oral, a suplementação alimentar e a distribuição de micro nutrientes. É no contexto dessas ações que se enquadraria a utilização da "multimistura", considerando-se que, se uma criança recebesse uma alimentação adequada, não teria necessidade de qualquer suplementação.

Diante desses pressupostos, surgem duas questões: $1^{\circ}$ ) a $\mathrm{MM}$ é realmente efetiva na recuperação de desnutridos? $2^{\circ}$ ) em caso afirmativo, sua adoção em nível de programa de saúde pública seria uma medida adequada para o controle do problema nutricional?

A partir dos resultados obtidos no presente experimento, aliados aos divulgados por outros autores, pode-se concluir que a "multimistura" parece suprir razoavelmente os requerimentos vitamínicos dos animais; porém, apenas parcialmente, suas necessidades minerais.

Parece óbvio que a MM carreie, em sua composição, determinada proporção de vitaminas e minerais capazes de suplementar a dieta habitual. No entanto, não constitui um suplemento plenamente confiável. Portanto, há necessidade de estudos que esclareçam quais suas reais potencialidades, de modo que sua utilização, em situações e contextos epidemiológicos específicos, possa ser indicada. A partir desse entendimento, recolocamos em discussão a segunda questão anteriormente apresentada: a adoção da "multimistura" em nível de programa de saúde pública seria uma medida adequada para o controle do problema nutricional? Sendo a desnutrição uma desordem biológica determinada segundo a inserção social do indivíduo, as principais medidas de ataque às suas causas básicas encontram-se fora do setor saúde, dependendo fortemente do nível de interesse do poder público em instituir políticas que efetivamente reduzam a miséria entre a população. Assim entendendo, a "multimistura" pode constituir-se em mais um recurso a ser utilizado pelos profissionais de saúde num âmbito restrito e localizado, mas não como política pública destinada ao controle da desnutrição em nosso País.

\section{REFER Ê NCIAS}

1. Ferreira HS, França AO. Evolução do estado nutricional de crianças internadas em um hospital universitário. J Pediatr. 2002; 78(6):491-6.

2. Ferreira HS. Desnutrição: magnitude, significado social e possibilidade de prevenção. Maceió: EDUFAL; 2000.

3. Monte CMG. Desnutrição: um desafio secular à nutrição infantil. J Pediatr. 2000; 76 (Supl 3): S285-97.

4. Lopez FA. Aspectos socioeconômicos da desnutrição no Brasil. In: Nóbrega FJ. Distúrbios da nutrição. Rio de Janeiro: Revinter; 1998. p.80-7.

5. Taddei JAAC, Sigulem DM. Epidemiologia. In: Nóbrega FJ. Distúrbios da nutrição. Rio de Janeiro: Revinter; 1998. p.71-9.

6. Ferreira HS, Albuquerque MFM, Ataíde TR, Morais MGC, Mendes MCR, Siqueira TCA, et al. Estado nutricional de crianças residentes em invasão do movimento dos Sem Terra. Fazenda Conceição, Porto Calvo - Alagoas. Cad Saude Publica. 1997; 13(1):137-9.

7. Ferreira HS, Assunção ML, Vasconcelos VS, Melo FP, Oliveira CG, Santos TO. Saúde de populações 
marginalizadas: desnutrição, anemia e enteroparasitoses em crianças de uma favela do Movimento dos Sem Teto, Maceió, Alagoas. Rev Bras Saúde Matern Infant. 2002; 2(2):177-85.

8. Mahler H. Present status of who's initiative, Health for all by the year 2000. Ann Rev Public Health. 1988; 9:71-97.

9. Brandão CT, Brandão RF. Alimentação alternativa. Bulletin II. Brasília: INAN; 1996.

10. Amâncio OMS, Lajolo FM, Santoro M, Nóbrega FJ, Queiroz SS, Farfan JA. Recuperação nutricional de grupos populacionais de baixa renda. Análise crítica. Cad Nutr. 1995; 9(3):1-4.

11. Azeredo VB. "multimistura": uma alternativa alimentar? Rio de Janeiro; 1999.

12. Bittencourt SA. Uma alternativa para a política nutricional brasileira? Cad Saude Publica. 1998; 14(3):629-39.

13. Conselho Federal de Nutricionistas. Posicionamento do Conselho Federal de Nutricionistas quanto à "multimistura". Brasília: CFN, 1996. (Mimeografado)

14. Farfan JA. Alimentação alternativa: análise crítica de uma proposta de intervenção nutricional. Cad Saude Publica. 1998; 14(1):205-11.

15. Ferreira HS, Seara LT, Assunção ML, Silva MJ, Francelino AA. Biodisponibilidade dos minerais da "multimistura". In: Anais do $1^{\circ}$ Congresso Latino-americano de Nutrição Humana,1999; Gramado, Brasil. Rio Grande do Sul: Conselho Regional de Nutricionistas; 1999. p.38.

16. Teodósio NR, Lago ES, Romani SAM, Guedes RCA. Regional Basic Diet from Northeast Brazil as a dietary model of experimental malnutrition. Arch Latinoamer Nut. 1990; 40(4):532-47.

17. Reeves PG, Nielsen FH, Fahey GC. AIN-93 purified diets for laboratory rodents: final report of the American Institute of Nutrition Ad Hoc writing Committee on the reformulation of the AIN-73A rodent diet. J Nutr. 1993; 123(11):1939-51.

18. Official methods of protein crude in animal feed and pet food. J Assoc Off Anal Chem. 1987; 70:907.
19. Siqueira EMA, Azevedo IT, Arruda SF, Lima SMD, Gonçalves CA, Souza EMT. Regional low-cost diet supplement improves the nutritional status of school children in a semi-arid region of Brazil. Nutr Res. 2003; 23(6):703-12.

20. Vieira, S., Hoffmann, R. Estatística experimental. São Paulo: Atlas, 1989.

21. Beausset I. Estudio de las bases científicas para el uso de alimentos alternativos en la nutrición humana. Brasília: INAN, 1992. (Mimeografado).

22. Madruga MS, Câmara FS. The chemical composition of "multimistura" as a food supplement. Food Chem. 2000; 68(1):4-4.

23. Cozollino SMF. Biodisponibilidade de minerais. Rev Nutr. 1997; 10(2):87-98.

24. Siqueira EM, Arruda SF, Sousa LM, Souza EM. Phytate from an alternative dietary supplement has no effect on the calcium, iron and zinc status in undernourished rats. Arch Latinoam Nutr. 2001; 51(3): 250-7.

25. De Angelis RC. Programas de combate à desnutrição. In: De Angelis RC. Fome oculta. São Paulo: Atheneu; 1999. p.217-9.

26. Câmara FS, Madruga MS. Conteúdos de ácido cianídrico, ácido fítico, tanino total e aflatoxina em uma preparação brasileira (Natal) de "multimistura". Rev Nutr. 2001; 14(1):33-6.

27. Arruda SF. Biodisponibilidade de sais minerais no suplemento alimentar "multimistura" como suplemento alimentar no tratamento de ratos desnutridos [dissertação]. Brasília: Universidade de Brasília; 1999.

28. Bicudo M, Maffei H, Cassetan M. Ganho ponderal de ratos desnutridos recebendo "multimistura" com diferentes proporções de farelos de cereais. In: Anais do $4^{\circ}$ Congresso Nacional da Sociedade Brasileira de Alimentação e Nutrição,1996; São Paulo, Brasil. São Paulo: Sociedade Brasileira de Alimentação e Nutrição; 1996.

29. Santos GT, Santos FSB, Jong EV. Avaliação do valor biológico da proteína de farinha de pena, suplementada com "multimistura", em dietas deficientes de sais minerais. In: Anais do $10^{\circ}$ Salão 
de Iniciação Científica, 1998; Porto Alegre, Brasil. Porto Alegre: UFRGS; 1998.

30. Bion FM, Pessoa DNP, Lapa MAG, Campos FACS, Antunes NLM, López SML. Uso de uma "multimistura" como suplementação alimentar: estudo em ratos. Arch Latinoam Nutr. 1997; 47(3):242-47.

31. Leite MS, Azeredo VB, Carmo MGT, Boaventura GT. Utilização da "multimistura" durante a lactação e seus efeitos na produção e composição do leite materno de ratas. Rev Nutr. 2002; 15(2):211-21.

32. Azeredo VB, Dias MM, Boaventura GT, Carmo MGT, Fernandes NR. Influência da "multimistura" na gestação de ratas: pesos materno e fetal e triglicerídeos séricos. Rev Nutr. 2003; 16(1): 83-91.

33. Prefeitura Municipal de Belo Horizonte/Secretaria Municipal de Saúde. Programa de Prevenção e Combate à Desnutrição (PPCD). Relatório de Avaliação. Belo Horizonte, 1997. (Mimeografado).

34. Monteiro CA, Zúñiga HP, Benício MHA, Victora CG. Better prospects for child survival. World Health Forum. 1989; 10(2):222-7.

Recebido para publicação em 6 de fevereiro de 2003 e aceito em 29 de junho de 2004. 